\title{
Rahvateadlase rännuaastad
}

\section{Anu Korb ja tema doktoritöö Siberi eestlastest}

Rahvateadlase määratlemiseks on kasutatud mitmesuguseid võrdpilte. Antropoloogiaprofessor Justin Stagl näiteks võrdleb teda islami palveränduriga. Palveränd kuulub "islami viie samba" hulka ja on kõigile usklikele kohustuslik. Sõna moslem semantilisse kogukirjesse kuulub reis Mekasse, mistõttu võib nimetatud väljendiga tõelise ühenduse saavutada vaid see, kes on käinud pühas linnas; ta võib kanda aunimetust hadši.

Võrdluse aluseks rahvateadlasega on siin loomulikult välitööd. Välitööd, mis ühelt poolt on rahvateadlasele andmete kogumise meetod, teiselt poolt aga isiksust arendav kogemus.

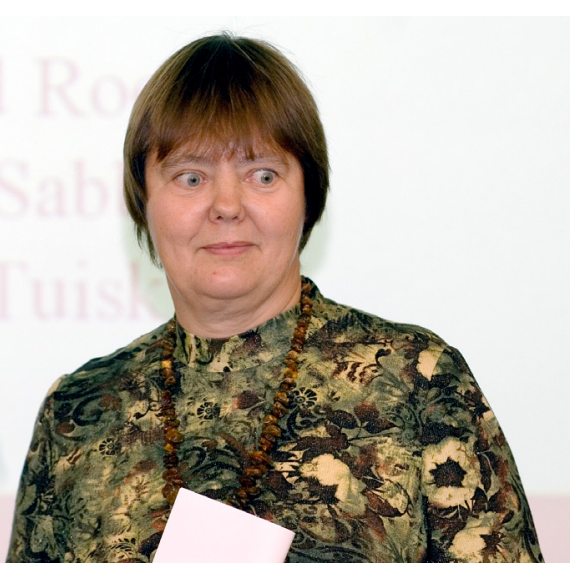
Kirkaid värve kasutades ja pisut ülepakkuvalt öeldes, et uurija saab välitöödel uueks inimeseks, jõuame järgmise assotsiatsioonini, mis iseloomustab rahvateadlast kui uurijat tema uuritavast teemaderingist pärineva kultuursõnaga. Selleks sõnaks on "initsiatsioon". Prantsuse antropoloog Claude Lévi-Strauss on siinkohal viidanud ka paralleelidele reisidega oma sisemise Mina avastamiseks, kuid seos jääb sisuliselt samaks. Eks ole psühhoanalüüski kõrvutatav initsiatsiooniga.

Olulise tähiseni rahvateadlase reisil on jõudnud Eesti Kirjandusmuuseumi rahvaluule arhiivi teadur Anu Korb, kes 28. augustil 2007 kaitses Tartu Ülikooli nõukogu saalis doktoritöö Siberi eesti kogukonnad folkloristliku uurimisallikana (Dissertationes folkloristicae universitatis Tartuensis 8. Tartu Ülikooli Kirjastus, retsensendid PHD Kristin Kuutma, PHD Aivar Jürgenson).

Just Anu Korbi puhul on võrdlused palverännu või initsieeriva reisimisega omal kohal, sest vähe on Eestis rahvateadlasi, kelle teadustöö on nii tihedalt põimunud välitööga. Ja vähe sellest - oma doktoritöös tunnistab Anu Korb isegi, et just ekspeditsioonid on vorminud temast kui arhiivitöötajast ja rahvaluule talletajast teadlase. Kogutud materjali on Anu Korb talletatud Eesti Rahvaluule Arhiivi, suur osa sellest on ilmunud ka tema alustatud tekstiantoloogiates Eesti asundused (neli kommenteeritud valimikku aastatest 1995-1999).

On siis ka loomulik, et doktoritöös toetub Anu Korb peamiselt enda kogutud materjalile. Viimast pole kuueteistkümne aastaga, mille jooksul Anu Korb on olnud Siberi eestlastele pühendunud, kogunenud sugugi vähe. Tartu Ülikooli dissertatsioonide sarja mahukasse köitesse on koondatud kaks hiljuti ilmunud monograafiat: Venemaal rahvuskaaslasi küsitlemas. Folkloristliku välitöö metoodilisi aspekte. Studia Ethnologica et Folkloristica Tartuensia 9 (toim Ene Kõresaar, Tiiu Jaago; Tartu: Tartu Ülikooli Kirjastus 2005, 158 lk) ja Rõžkovo virulased pärimuskultuuri kandjaina. Eesti Rahvaluule Arhiivi Toimetused. Commentationes Archivi Traditionum Popularium Estoniae 24 (toim Mall Hiiemäe, Kadri Tamm); Tartu: Eesti Kirjandusmuuseum 2007, 
$216 \mathrm{lk}$ ). Esimeses keskendutakse pärimusmaterjali kogumisele, kogumissituatsioonile ja kogumismeetoditele, teises analüüsitakse diasporaa-kogukonna pärimust tema muutumisprotsessis Lääne-Siberis asuva Rõžkovo küla näitel. Esimese doktoritööd moodustava raamatu kohta võib öelda, et teost saab kasutada käsiraamatuna rahvaluule kogumistöö planeerija või ka muidu Venemaale pikemale reisile siirduja. Korduvalt toonitatakse Venemaa eestlaste külalislahkust ja avatust, seda, et uurija saab Venemaal informantidega kontakti paremini kui Eesti külas. Seda võivad kinnitada nähtavasti kõik Venemaa asundustes töötanud rahvateadlased. Kindlasti on Anu Korbi tööle kasuks tulnud autori pikaaegne rahvaluulearhiivis töötamise kogemus: hea pärimuse tundmine ühelt poolt, arhiivi ühisekspeditsioonide kogemus ja orienteerumine kogumismetoodikas.

Pikalt peatutakse uurimuses uurija ja uuritava kontaktil ning kommunikatsiooni loomisel. Paratamatu teemana tuleb sisse usalduse küsimus: mida teha selleks, et informant avaneks? Anu Korb kirjutab neljasilmavestluste eelistest, eriti privaatsfääri kuuluva informatsiooni puhul, samas esitab ka vastupidiseid näiteid, kus informandi jutt hakkab eriti hästi jooksma just lugudega hästi tuttava isiku juuresolekul. Kirjutatakse nö võõra väärtusest: võõrale usaldatakse või ta võib küsida asju, mis pole seesolijatele lubatud. Ka selle kohta on ilmselt kõikidel staažikatel välitöödel käijatel kogemusi. Head näited on alapeatükis "Pärimusekandja enesekontroll", kus näidatakse, kuidas inimestele tekitab probleeme obstsöönse sisuga pärimustekstide esitamine. Sama kehtib salajase või privaatsfääri kuuluva informatsiooni kohta.

Teine doktoritöösse lülitatud raamat Rõžkovo virulased pärimuskultuuri kandjai$n a$ käsitleb vanimat luterlaste asundust Siberis, mis asutati 1803. aasta paiku. Küla on Siberi asunduste seas mitmes suhtes unikaalne. Segaasustus ja kultuurikontaktid on vorminud asunike pärimust ja keelekasutust. Huvipakkuv on peatükk "Keeleline identiteet rahvuskuuluvuse määrajana". Usulise ja etnilise identiteedi segunemine, etnilise identiteedi ähmastumine - selliste nähtuste uurimiseks pakub Rõžkovo oma ajaloolisest taustast tingituna hea võimaluse. Tuuakse välja, et Rõžkovos tähistab mõiste virulane nii eestlasi kui ka soomlasi, samal ajal kui teistes külades on virulane eestlaste enesenimetus. Samuti, et Rõžkovos võidakse peaaegu sünonüümidena kasutada nimetusi virulane, eestlane, soomlane. Lisaks keelesuhetele Rõžkovos on selles raamatus vaadeldud kogukonna laulurepertuaari, rahvakalendrit, rahvameditsiini ja matusekombestikku - tegemist on seega vaid valikuga rahvakultuuri kaanonisse kuuluvatest valdkondadest, kuid et Anu Korb on oma kogumistöös Siberi eesti külades neile valdkondadele rohkem tähelepanu pööranud ja orienteerub neis ilmselt parimini, on valiku printsiip mõistetav.

Kuigi Rõžkovo näib Anu Korbi doktoritöös kajastatuna mõneski mõttes erandlik teiste Siberi külade seas, on siin ometi palju Siberi eestlastele tüüpilist, mistõttu võib käesolevast raamatust saada päris hea ülevaate Siberi eestlaste rahvatraditsioonist tervikuna. Läbilõiget süvendavad ka ohtrad paralleelid, mida Anu Korb suudab pakkuda tänu oma heale orienteerumisele Siberi eestlaste rahvapärimuses.

Doktoritöös leidub mitmeid uuenduslikke momente. Näiteks võib tuua Siberi eesti asunduste liigituse, mis võtab aluseks asunduste rajajate päritolu ja eestlaste osatähtsuse asundustes tänapäeval. Arvestades praegust situatsiooni, kus eestlaste arvukus ja osatähtsus asundustes kahaneb, ei piisa enam August Nigoli (1918. aastal ilmunud Eesti asundused ja asupaigad Venemaal. Tartu) aegsest liigitusest ning Anu 
Korbi pakutu on hästi õnnestunud. Et lõviosa Siberi eestlastest elab tänaseni maapiirkondades, keskendub autor nii oma kogumis- ja uurimistöös kui ka antud liigituses Siberi eesti maaelanikele. Samas tuleks edaspidi arvestada veel ühe asjaoluga. Nimelt on 20. sajandi jooksul paljud Siberi eestlased asunud elama linnadesse (4100st Krasnojarski krai eestlasest tuhatkond elab Krasnojarski linnas), mistõttu tuleks omaette kategooriana lisada linnaelanikud, edaspidi ehk neid ka suuremal määral uurida.

Peamiselt keskendub Anu Korb oma doktoritöös välitöö, spetsiifilisemalt folkloristliku välitöö kui andmete kogumise analüüsile. Ridade vahelt paistab aga läbi toosama välitöö kui isiksuse transformatsiooni küsimus, siirderiituse küsimus.

Pole ilmselt ülearune märkida sedagi, et Anu Korb on välitöö initsieerivat kogemust jaganud lahkesti paljudele noorematele rahvateadlastele ja seda puhtpraktiliselt. Allakirjutanugi sattus Siberisse sealseid eestlasi küsitlema tänu Anu Korbile, kes ta aastal 1996 kaameramehena Omski oblastisse kaasa võttis ja süstis temasse huvi selle diasporaarühma vastu. Koos käisime Siberis ka järgmisel aastal. Mitmed teisedki rahvateadlased on Siberi eestlasteni jõudnud tänu Anule ja see, et tänaseks on Siberi eestlased ilmselt kõige rohkem teaduslikku käsitlemist leidnud eestlaste diasporaarühm, on suuresti just tema teene. Mitte kõik teadlased pole vaevunud endale järelkasvu kasvatama. Talle on võõras see kohati teadlastele omane hoiak, mis tõrjub "konkurente" "minu rahvast" eemale; see sageli kõrgilt autentsuse nõudele apelleeriv immuniseeriv strateegia, millega mõned teenekad uurijad peavad mõnda rahvakildu oma uurimismonopoliks, privaatterritooriumiks, kuhu teistel asja ei ole. Nii jääb Anu puhul ära ka interpreteerimismonopoli probleem: avatus ja abivalmidus, millega ta noorematesse kolleegidesse alati on suhtunud, tema respekt nende arvamuste ja tõlgendusviiside suhtes, on aidanud kujundada Siberi eestlaste uurijate koolkonna, kellelt võib lähiaastatel küllap veel palju põnevat oodata.

Aivar Jürgenson

\section{Keelest meeleni}

\section{Ülo Tedre 80}

12. veebruaril 2008. aastal tähistas oma 80. sünnipäeva eesti folkloristika grand old man Ülo Tedre. Eesti ühe nimekaima, mitmekülgseima ja viljakaima rahvaluuleteadlase sulest on ilmunud ligi 400 kirjutist kultuuriloo, keeleteaduse, kirjanduse ja folkloristika alalt. Ta on koostanud kultuuriloolisi kaarte (teostus Olev Soans) ning kirjanike teoste kogumikke (nt Karl August Hindrey), olnud nende toimetaja (Jaan Krossi romaanisari). Rahvaluule alal on tema vaadeldud temaatika olnud väga ulatuslik: mainigem siinjuures uudseid teoreetilisi lähenemisi uuematele ja vanematele lauludele, rahvajuttudele ja kombestikule. 
Väärikale folkloristile oli pühendatud 20. ja 21. veebruaril Tallinnas EELK Usuteaduse Instituudis interdistsiplinaarne teaduskonverents "Keelest meeleni 2". Nii nagu lai haare ja suur teadmus iseloomustavad Ülo Tedret, nii iseloomustas mõtte- ja teema-avarus ka kahel konverentsipäeval peetud ettekandeid.

Konverentsi avaettekande "Inimene ja tema raamatud" pidas Janika Kronberg, kes rääkis isikuraamatukogudest ning arutles, milline on raamatutarkuse ja elukogemuse määr inimese elus ja töös, elutarkuse ja raamatutarkuse vahekord. Kuivõrd mõeldav on raamatukogu järgi ette kujutada ja rekonstrueerida isiksust, kellele see kuulub või on kuulunud, teadmata temast muud. Kõneldes folkloristile, piibumehele ja raamatusõbrale Ülo Tedrele, mõtles Kronberg piibumehele ja etnoloogile Ilmar Talvele ning peatus põhjalikumalt Talve isiklikul raamatukogul, mille erinevad tahud (oli ju omanik ise ühtaegu nii teadlane (etnoloog) kui ka looja (kirjanik)) viitavad elutarkuse ja raamatutarkuse tasakaalule.

Urmas Sutropi ettekanne andis ülevaatliku pildi Eesti jumalate, sh Taara kirjelduste ja esemete põhjal kujutamisest. Varasematest (sh linnukujulistest) jumalatest leiab märkmeid Breemeni Aadamalt, Henriku Liivimaa kroonikast, Johann Christoph Brotzelt jt. Võrdlusmaterjalina kasutati meie sugulasrahvastel tuntud jumalakujutisi (nt saami kivikujusid ja šamaanitrummidel kujutatud Tiermest). 18. sajandi teisest poolest pärinevad teated Taara käsitlemisest kunstis. Ettekandja lähtus osavast 18. sajandil Neubrandenburgi lähedal loodud võltspanteonist ja tutvustas, kuidas loodud kujud said teaduslikus diskursuses tuntuks slaavlaste eelkristlike jumalatena. Kujudele omaloodud ruunikirjas lõigatud nimed aitavad neid identifitseerida, muude hulgas leidub seal ka soomlaste jumal Taara.

Asta Õimu ettekanne "Kvantiteedist eesti fraseoloogias" käsitles tüüpilisi vormilisi ja vähemal määral semantilisi kvantiteedi väljendamise võimalusi. Rikkaliku näitematerjali varal demonstreeris esineja kognitiivselt omandatud kvantiteedisuh-

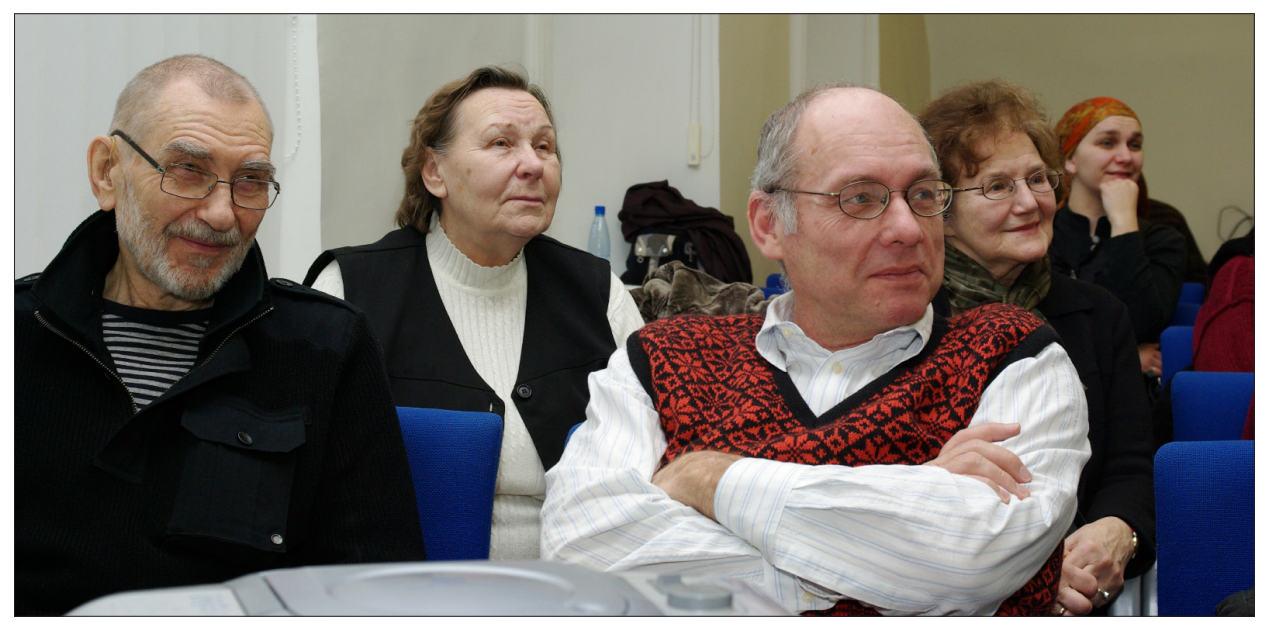

Ettekandeid kuulavad Veljo Tormis, Elvi Pillesaar, Harry Mürk, Ruth Mirov, Mari Sarv. Andres Kuperjanovi foto 2008. 
teid, mis põhinevad kas objektide omavahelisel võrdlusel ja gradatsioonil (kedagi võrreldakse igapäevaste käepäraste esemetega) või objektide võrdlemisel inimese enda parameetritega või kogemuslikul normil "tavaline" - ei vähe ega palju. Kvantiteet avaldub implitsiitselt tajutava keskmise normi suhtes. Fraseologismide kvantitatiivsuse analüüsi aluseks võttis Asta Õim absoluutse superlatiivi käsitluse keskmisest normist ja piirnormist: keskmine norm (vana) - keskmisest suurem norm (väga vana) - piirnorm (puruvana).

Nikolay Kuznetsov vaatles miljonist sõnast koosneva keelekorpuse najal lähikohakäändeid. Ettekanne "Kuidas joonistada käänet. Komi kohakäänded kognitiivsest aspektist" tugines Ronald W. Langackeri kognitiivse grammatika printsiipidele. Uusimas komi keele grammatikas on 22 käänet, millest 13 osutavad kohasuhetele. Siseja väliskohakäänded on laialt levinud, lähikohakäänded on hilistekkelised, nende käänete sufiksite ühine osa on -lan'.

Ljudmila Lobanova ettekanne "Suure neljapäeva karjakasvatusrituaalid komidel" osutas, et mütopoeetilisest aspektist assotsieerub suur neljapäev uusaastaga. Provisoorne analüüs näitab, et mõlemas esineb initsiaalset sümboolikat, mis tähistab vana lõppu ja uue algust, ja nad on seotud uuenemise ideega. Vaatluse all oli ka suurele neljapäevale eelnev päev, komidel nõidade käimise päev, karjaloomade märgistamise päev. Suure neljapäeva hommikul läbiviidavad rituaalid on suunatud kariloomade kaitsmisele ning karja suurendamisele ja tugevdamisele.

Arvo Krikmann iseloomustas ettekandes "Eestlased, soomlased, lätlased ja leedulased vene netinaljades" etnilise nalja objektide muutumist Eestis 19. sajandi lõpust 20. sajandi lõpuni ning Venemaal nõukogude ajal ja pärast Nõukogude Liidu lagunemist, samuti käsitles ta netinaljade põhiliike (staatilised kontekstitud, staatilised kontekstilised, dünaamilised kontekstitud ja dünaamilised kontekstilised). Naljade internetti kolimise järel on vene saidid ilmselt kõige võimsamad naljaallikad kogu maailmas. Iseäranis huviväärne on eestlase kui etnilise stereotüübi (nt kuumad eesti poisid) kasutamine vene naljades ning skriptid (esijoones aeglus), millel vastavad naljad põhinevad.

Folkloori etnilistele aspektidele oli üles ehitatud ka Mare Kõiva ettekanne "Kuue rahva stereotüübid". Ettekande allikmaterjal põhines aastate 1996-2002 küsitlustel, kus paluti esitada eelarvamusi ja stereotüüpe oma ja kuue naaber- või kaugema rahva kohta. Põhiosa ettekande tsiteeringuist pärines kultuuridevahelise kommunikatsiooni projekti "Babel" (Cross Cultural Exploration \& Dialog, 1996) vastustest, milles 30 maa üliõpilasrühmad kirjeldasid etnilisi stereotüüpe. Esineja püüdis avada etnilise stereotüübi olemust ja lähtus seisukohast, et stereotüübi näol on tegemist vale või liiase üldistusega mingi rühma kohta, kusjuures üldistus ei laiene rühma üksikliikmetele.

Etnomusikoloog Taive Särg süüvis ettekandes "Tänapäeval loodud pärimusmuusika. Ansambel Laudaukse Kääksutajad” mõistete rahvamuusika, traditsiooniline muusika ja pärimusmuusika vahekordadesse. Ansambel Laudaukse Kääksutajad on esitanud regivärsilisi tekste omaloodud viisidega. Taive Särg osutas erinevustele ansambli muusikaloomingu ja eesti ajaloolise pärimusmuusika vahel.

Aado Lintropi ettekanne "Alliteratsioon obiugri rahvaluules" vaidlustas rikkaliku näitematerjali varal paljude varasemate uurijate (nt Robert Austerlitzi) seisukohtad alliteratsiooni puudumisest obiugri folklooris. Analoogiliselt parallelismile, mis obiugri 
poeesias väljendub peamiselt ühe sõna poolest erinevate värsside kordamises, ilmneb alliteratsioon sõnatüvede kordamise ehk etümoloogilise kujundi (figura etymologica) rakendamisel.

Teist konverentsipäeva alustati leinaseisakuga, meenutamaks 20. veebruaril meie hulgast lahkunud kauaaegset murdeuurijat, Emakeele Seltsi auliiget Mari Musta. Teenekas keeleteadlane oli viimastel aastatel seotud Asta Õimu juhitud fraseoloogia-projektiga.

Mare Kalda tutvustas ettekandes "Diskursiivne aardeväli tegelikkuse skaalal" aardepärimuse põhjal loodud analüütilist mudelit kui uurimisaine üht võimalikku kirjeldusviisi. Mudeli väljatöötamise lähteks oli uurija võtnud küsimused, mil määral on tegu teadetega tegelikkusest; kuidas suhestuvad jutud peidetud varandusest juttude teadjate füüsilise maailmaga; kuidas (ja miks) liigitada folkloorseid jutte ja teateid diskursusesisesteks üksusteks; kuidas paigutuvad jutud ja teated diskursiivsel aardeväljal folkloori žanrisüsteemi. Uurimisküsimuste vastuseks on uurija subjektiivsete otsustuste põhjal joonistuv skeem, kus eri jututüübid paiknevad tegelikkuse ja fiktsiooni vahelisel horisontaalsel skaalal, uurimisaines on korrastunud.

Katre Kikas oli oma ettekande teemaks valinud Koeru kihelkonnast pärit folkloorisaatja, 1905. aastal hukkunud rätsep-revolutsionääri Hans Anton Schultsi saadetised ja 1982. aastal Richard Viidalepa sulest Keeles ja Kirjanduses ilmunud artikli "Hans Anton Schults ja Jakob Hurt". Ettekande alapealkiri "Järelmärkusi Richard Viidalepa lugemisele” pööras tähelepanu sellele, kuidas kirjasaatja luges J. Hurda kirju, millised tegurid mõjutasid tema lugemist ja miks ta saatis just seesugust materjali. Teoreetilise raamistusena kasutas K. Kikas Jonathan Fabiani ideed rohujuure tasandi kirjalikkusest (grassroot literaracy) ning David Bartoni ja Mary Hamiltoni ideed rahvalikust kirjalikkusest (vernacular literacy).

Jaan Unduski ettekanne "Pagulaskirjandus - kas tõsi- või väljamõeldis" käsitles väliseesti ja pagulaskirjanduse mõistete problemaatikat. Esinejat huvitas mõiste kasutus laiemalt, kas väliseesti kirjandus on eesti kirjanduse poliitiliselt välistatud osa ja eesti kirjandus sisemine teine või tuleb lähtuda ideoloogilisest soovunelmast, et eksisteerib üks ja ainus eesti kirjandus. Undusk näitas mõiste erinevaid kasutusvälju alates 1950. aastatest eksiilis, kus ühed (nt Ilmar Talve) pidasid tähtsaks rääkida pagulasrühmast ja pagulaskirjandusest (kui millestki ajutisest, mis aitab hoida kultuurilist sidet kodueesti kultuuriga), ning teised (nt Karl Ristikivi) eelistasid pagulaskirjanduse asemel rääkida eesti kirjandusest või kirjandusest üldiselt (jääda eestlaseks, kuid mõelda maailmamastaabis). Kolmeastmeline skeem - pagulane (pagulaskirjanik), eestlane (eesti kirjanik) ja inimene (kirjanik) - võimaldab hõlmata vastandlikud leerid ühele skaalale.

Veljo Tormise etteaste "Ülo Tedre ja eesti muusika" peatus juubilaril kui traditsioonilise koorikultuuri kandjal, Eesti Teaduste Akadeemia Meeskoori asutajaliikmel ja 1958-1984 lauljal. V. Tormis tõi esile, et Ülo Tedre publikatsioonid suunasid muusikalise folkloori harrastajaid, rahvalaulu uuel ärkamisajal 1970. aastail lõi ta kaasa, koostades Regilauliku ja tuues kasutusele regilaulu teadusterminina. Ülo Tedre on olnud Veljo Tormise regilaululiste teoste tekstiseadja ja -koostaja. Ettekandesse oli põimitud neli helinäidet: 1970. aastast pärit salvestis laulust "Eesti mullad", milles Ü. Tedre laulis tenorit; RAM-i mõne aasta tagune koorilaulusalvestis "Nekruti 


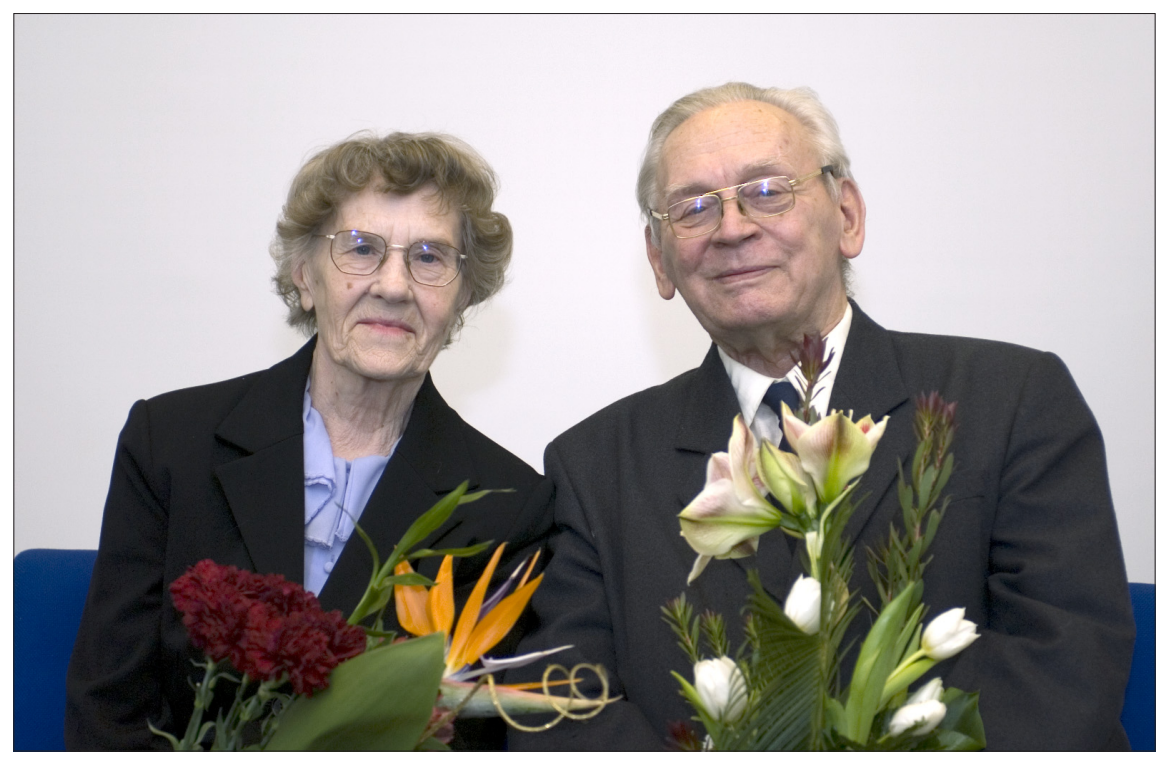

Ülo Tedrele toodud lilli jagus sülle nii talle endale kui ka abikaasale Virma Murelile. Alar Madissoni foto 2008.

põgenemine Tallinna Toompealt koju Kuusallu"; Mare Jõgeva esituses regilaul "Mehetapja" teosest "Eesti ballaadid" ja Eesti Poistekoori esituses Venno Laulu juhatusel Haljala "Reelaul".

Esimese konverentsipäeva lõpuks olid pikaaegset osakonnajuhatajat ja folkloristi õnnitlema kogunenud praegused ja endised kolleegid kirjandusmuuseumist, Eesti Keele Instituudist, Underi ja Tuglase Kirjanduskeskusest, Emakeele Seltsist ning paljudest institutsioonidest, millega Ülo Tedre seotud on olnud; esitleti Karin Maria Rooleidi koostatud Ülo Tedre bibliograafiat.

Kaks sisutihedat ettekandepäeva lõpetas ekskursioon vaid aasta eest Linda- ja Harjumäe all külastajatele tutvumiseks avatud Rootsi ja Ingeri bastionide käikudesse. Teise maailmasõja ajal, mil käike kasutati pommivarjendina, õnnestus toona 16aastasel Ülo Tedrel Tallinna märtsipommitamise esimene laine just seal üle elada. Asjatundliku giidi Kristiina juhatusel kuuldi 400-meetrise retke vältel 17. sajandil rajatud muldkindlustuste ja käikude ajaloost, nähti ladestunud stalaktiite ja loodeti kohata Eestis haruldast ämblikuliiki, valgust kartvat Meta menardit ehk Euroopa koopaämblikku. Folkloristidele oli professionaalselt huvipakkuv giidi jutustatud kummituslugu mustast mungast, kes olevat end kunagi käikudes ilmutanud.

Eesti Kirjandusmuuseumi folkloristika osakonna ja Eesti Folkloori Instituudi korraldatud teist korralist teaduskonverentsi sarjast "Keelest meeleni" toetas riiklik programm "Eesti kirjandusklassika". Konverentsi kava, teeside ja fotodega saab tutvuda ürituse kodulehel http://www.folklore.ee/rl/fo/konve/2008/km2/.

Piret Voolaid 


\section{NEWS IN BRIEF}

\section{Travels of an Ethnologist: Anu Korb and Her PHD Dissertation on Estonians in Siberia.}

On August 28, 2007 Anu Korb defended her PHD thesis on Estonian communities in Siberia as a source for folkloristic research (Siberi eesti kogukonnad folkloristliku uurimisallikana. Dissertationes folkloristicae universitatis Tartuensis, 8. Tartu Ülikooli Kirjastus) in the Senate Hall of the University of Tartu. Overview of the thesis defence by Aivar Jürgenson is available in English in volume 37 of Folklore: Electronic Journal of Folklore (http://www.folklore.ee/folklore/vol37/news.pdf).

\section{Conference in Honour of Ülo Tedre's 80th Birthday}

Piret Voolaid reviews the interdisciplinary academic conference From Language to Mind, Vol. 2, held in honour of Ülo Tedre's 80th birthday held at the Tallinn Institute of Theology on February 20-21, 2008. 